\title{
Metastatic Liver Carcinoma
}

National Cancer Institute

\section{Source}

National Cancer Institute. Metastatic Liver Carcinoma. NCI Thesaurus. Code C154088.

A carcinoma that arises from the liver and has spread to another anatomic site. 